\title{
NAGOYA
}

\section{MATHEMATICAL JOURNAL}

\section{VOL. 137}

\author{
March 1995
}

PUBLISHED BY

DEPARTMENT OF MATHEMATICS, SCHOOL OF SCIENCE NAGOYA UNIVERSITY 
Correspondences concerning subscription, and back issues of the journal should be addressed to

KINOKUNIYA COMPANY LTD.

17-7 Shinjuku 3-chome, Shinjuku-ku

Tokyo 163-91 JAPAN

The annual subscription price for 1995 is about $\$ 339.00$ 


\section{NAGOYA}

\section{MATHEMATICAL JOURNAL}

\section{VOL. 137}

March 1995

Editors

KaZuhiko Aomoto, Tadahisa Funaki, Yoshiyuki Kitaoka, Ryoichi Kobayashi, Shigeru Mukai, Takeo OHSaWa, Yoshiniro ShIKATA (Managing Editor), AKIHIRo TSUCHIYA

Associate Editors

TAKeyuki Hida, Noboru Ito, Tomio Kubota, Hideyuki Matsumura, Shigefumi Mori, Hisasi MoRiKawa, AKiniko Morimoto, KatuZi ONo, Toshikazu Sunada NAGOYA UNIVERSITY 
Nagoya Mathematical Journal is, in principle, the official organ of the Department of Mathematics, Nagoya University, designed solely for the publication of research papers. However, some invited papers and other original papers in mathematics from all over the world are also regularly published in Nagoya Mathematical Journal. Currently, 4 volumes are published each year.

All manuscripts should be typewritten in English, French, or German. Special letters such as bold-face, German, Greek, and script should be clearly distinguished. Mathematical symbols should appear in the standard style usual for mathematical literature.

Classification numbers from the American Mathematical Society's classification scheme should appear at the bottom of the first page of the manuscript.

Authors are requested to submit a copy with their original manuscript.

As soon as we receive a manuscript, a receipt will be sent to the author. When a manuscript has been sent to a referee, the author will receive another notice. These receipts and notices, however, do not mean anything regarding the acceptability of the paper for publication. If the editorial committee has decided to accept a paper, the author will receive a notice containing the number of the volume in which the paper will appear.

Each author, as well as each co-author, will have 100 reprints, while only one set of proof will be prepared per paper for proof-reading by the author(s). Therefore, a joint paper must carry instructions as to whom the proof should be sent.

The manuscript and general correspondence should be addressed to: Managing editor, Nagoya Mathematical Journal, Department of Mathematics, School of Science, Nagoya University, Chikusa-ku, Nagoya, 464-01, Japan. 


\section{CONTENTS}

Lanteri, A., Palleschi, M. and Sommese, A. J.: Double covers of $\mathrm{P}^{n}$ as very

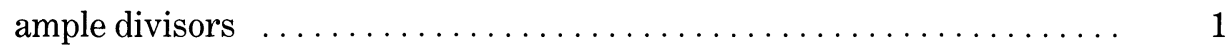

Tasaki, H.: Integral geometry under cut loci in compact symmetric spaces 33

Graversen, S. E., Peškir, G. and Weber, M.: The continuity principle in

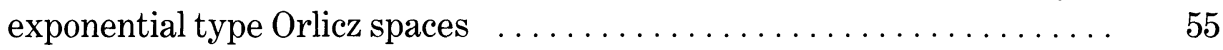

Hill, R.: A geometric proof of a reciprocity law $\ldots \ldots \ldots \ldots \ldots \ldots$

Ohsawa, T.: Addendum to "On the Bergman kernel of hyperconvex

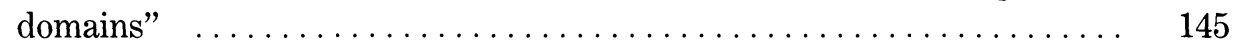

Itoh, M.: The Weitzenböck formula for the Bach operator . . . . . . . . . 149

Colţoiu, M. and Silva, A.: Behnke-Stein theorem on complex spaces with

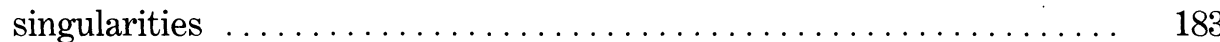

Kang, H. and Seo, J.: Errata for " $L^{2}$-boundedness of the Cauchy transform

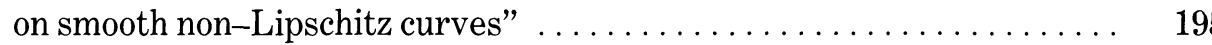

